\title{
Structural and intermediary determinants of social inequalities in the mental well-being of European workers: a relational approach
}

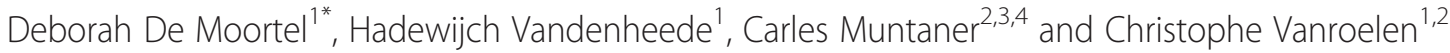

\begin{abstract}
Background: The objective of this study is to examine social inequalities in employee mental well-being, using relational social class indicators. Relational social class indicators are based on theoretical insights about the mechanisms generating social (health) inequalities. Additionally, it is examined whether the psychosocial work environment and employment quality act as intermediary determinants of social class inequalities in mental well-being, simultaneously testing the mediation (differential exposure) and moderation (differential vulnerability) hypotheses.

Methods: Data from the European Social Survey Round 2 (2004/5) and Round 5 (2010) were analysed. Mental well-being was assessed by the WHO Well-being Index. The measure for social class was inspired by E.O. Wright's class scheme. Three-level linear multilevel modelling was used to account for clustering of employees within research years and countries.

Results: We found social class inequalities in mental well-being in the European working population for both men and women. Compared to unskilled workers, managers reported the best mental well-being, while supervisors held an intermediary position. As regards the mediation hypothesis, an unfavourable psychosocial work environment and low-quality employment conditions mediated the relation between social class and poor mental well-being in both men and women. However, low quality of employment relations only mediated the "social class-mental well-being" association in the male sample. As regards the moderation hypothesis, modification effects were seen for the psychosocial work environment and employment conditions in both men and women.

Conclusion: Relational indicators of social class are related to mental well-being in European employees. Relational accounts of social class are complementary to stratification indicators in social epidemiology. From a policy perspective, better employee mental well-being and less social class inequality could be achieved through initiatives addressing the unequal social relations generated by structural positions in the labour process.
\end{abstract}

\section{Background}

Many studies have shown social gradients in physical ill health and mortality among employees across Europe: the lower workers' socioeconomic position, the higher their risk of poor health or mortality [1-3]. Social gradients among workers are also seen for serious mental illnesses and major depression $[2,4]$. However, the socioeconomic patterning of less severe mental health problems is less clear [5].

\footnotetext{
* Correspondence: ddemoort@vub.ac.be

'Department of Sociology, Vrije Universiteit Brussel, Pleinlaan 2, 1050 Brussel, Belgium

Full list of author information is available at the end of the article
}

Nevertheless, workers who are free from mental illness are not necessarily in good mental health [6]. Mental health is more than the absence of mental illness, but includes also a reflection of the presence of positive feelings and positive functioning in life [6,7]. The absence of positive feelings about life, such as feelings of stress or anxiety, is debilitating for the individual in various ways [8]. Research shows that these minor mental health problems among employees are an important cause of sickness absence and work disability [9]. Hence, their burden on society is quite heavy [8].

Studies investigating social inequalities in less severe mental health problems among employees show inconsistent results: some report a better mental health or 
well-being for employees in lower socioeconomic positions, while other studies find the associations to be statistically insignificant [10-13].

One of the reasons for contradictory findings might lie with the measures for socioeconomic position most researchers are using. Often they have no explicit underlying theoretical framework $[14,15]$. In empirical social epidemiological research, socioeconomic position is commonly measured as "social stratification" - that is, as a gradient based on for instance income or years/grades of education [16]. These measures typically do not reveal the social mechanisms that explain how individuals accumulate different levels of material and psychosocial resources [17]. Unlike measures of social stratification, relational social class indicators are based on theoretical insights about the mechanisms generating social (health) inequalities. Among workers, unequal social relations are generated by structural positions of dominance and subordination in the labour process. It can be assumed that these unequal relations are the core processes generating mental health inequalities. The social class approach represents thus a framework complementary to social stratification, tapping into parts of social health variations not captured by conventional measures of social stratification [18].

Another reason for contradictory findings might be the limited adequacy of a gradient approach for the identification of minor mental health problems related to specific "roles" in the production process. Previous research found better mental health in workers without supervisory authority than in low-level supervisors due to the special structural position of supervisors [16]. Supervisors are subjected to the pressure of upper management's control, while having responsibilities over subordinate workers. At the same time they exert little influence over company policy. In other words, because of their social role in the labour process, supervisors may have particular difficulties to deal with high demands and low control at work [16]. This finding gives support to Wright's "contradictory class location" hypothesis [19]. It can be assumed that the "contradictory class location" of supervisors is likely to result in poorer mental health, whereas lower classified workers are likely to have better mental health. Descriptive, gradient-wise indicators may "hide" less favourable mental health outcomes of higher classified groups [20].

First, more research is needed on social inequalities in minor mental health problems in European employees, using a relational social class approach and taking workers' specific roles into the production process into account. In this study mental well-being (as measured by the WHO Well-being Index) will be used as an indicator of minor mental health problems. High mental well-being is increasingly recognised by policy makers and health advocates as an indicator of good mental health [21]. Second, the role of contemporary work and employment arrangements in the relationship between social class and employees' well-being should be explored. Previous research showed that exposure to adverse work and employment characteristics is mediating (explaining) the association between social class and self-reported health: workers in less empowered, more exploited classes are more frequently exposed to adverse work and employment characteristics, than workers in more empowered, less exploited classes [18]. However, adverse work and employment exposures could also moderate the relation between mental well-being and social class, in the same way as these exposures have shown to moderate the relation between measures of social stratification and health outcomes [22]. In other words, workers in less empowered, more exploited classes could be more vulnerable to adverse work and employment characteristics, resulting in worse mental well-being, compared to more empowered, less exploited classes. Both differential vulnerability and differential exposure of employees to adverse work and employment characteristics should be examined when studying social inequalities in mental well-being.

\section{Structural and intermediary determinants of mental health inequalities}

Mental health inequity has structural and intermediary determinants in which structural determinants come first in the causal process $[23,24]$. Structural determinants of health inequalities are social, economic and political mechanisms which generate social class inequalities in society [24]. Social class can be considered a structural determinant of mental health, while situational characteristics (such as job quality) can be considered as a mechanism interfering with the relation between social class and mental health.

According to Wright [25], employees sell their labour power to the owners of productive assets (employers) who extract labour effort from them. Some employees, such as managers and supervisors, receive delegated authority from employers: they have the power to supervise subordinates and give them positive and negative sanctions. Managers and supervisors dominate (hire, fire, promote, demote) subordinates, but are controlled by employers themselves. This is why Wright [25] argues that supervisors and managers occupy a contradictory location within class relations. Managers and supervisors also differ from each other: managers are able to influence organisational decision-making, while supervisors are not [25]. Furthermore, employees who possess high levels of skills (so-called "experts"), are potentially in a privileged appropriation location within the class structure, because their specific skills or expertise are highly valued on the labour market [25]. Emphasising individuals' location within 
these structural sets of relations calls attention to the on-going tensions between managers, supervisors and workers with different levels of skills and expertise, generating social inequalities in mental health [19]. A Spanish study found that the repeated experience of organizational control at work protected most upper-level managers against mood and anxiety disorders. This study also showed that low-level supervisors reported higher rates of depression and anxiety than both high-level managers and non-supervisory workers. Moreover, experts were found to enjoy better health than non-experts [16]. We hypothesize that in the European employee population, compared to workers, managers report better mental well-being, while supervisors present worse mental wellbeing. We furthermore expect experts to report better mental well-being than non-expert employees.

The position in the class structure also shapes specific determinants of health status [24]. As mentioned earlier, based on their class position, individuals experience differences in exposure and vulnerability to healthcompromising conditions [26,27]. These conditions, such as unfavourable working conditions, operate as intermediary determinants of health inequalities. In empirical studies, intermediary determinants of health inequalities among workers are usually assessed through indicators of the psychosocial work environment [2,28]. For instance, using the Demand-Control model: high psychological demands have a detrimental effect on mental health, while high job control is related to better mental health [29]. However, compromised employment quality is also found to be negatively associated with mental health [30]. Employment quality encompasses two conceptual dimensions: employment conditions (contract security, working times, income and rights, and employability) and employment relations (empowerment and representation) [31]. Both studies on employment conditions and studies on employment relations found negative associations with workers' well-being [32,33]. We hypothesize that the association between social class and mental well-being can partially be explained by differential exposure (the mediation hypothesis) and differential vulnerability (the moderation hypothesis) to the psychosocial work environment, employment conditions and employment relations.

\section{Methods}

Data

This study is based on secondary data, namely on a pooled dataset of Round $2(2004 / 5)$ and 5 (2010) of the European Social Survey (ESS). In these rounds, the questionnaire contained a supplementary module on family, work and well-being. Due to the exclusive use of secondary data (ESS data), which is available to the public, no ethical approval is required for this study. The ESS includes representative samples of persons aged 15 and over, who are resident in European countries. This study focuses on European wage earners. Respondents not in waged employment or older than 65 were excluded from the analyses. In addition, only data from countries that participated in both ESS rounds were retained. This left us with data from 19 European countries (Belgium, Czech Republic, Denmark, Estonia, Finland, France, Germany, Greece, Hungary, Ireland, Netherlands, Norway, Poland, Slovakia, Slovenia, Spain, Sweden, Switzerland, and United Kingdom) to analyse, and a total sample of 15,030 male and 14,683 female employees. For the multivariate analyses, we applied complete case analysis reducing the number of respondents to 14,583 male and 14,164 female employees.

\section{Measures}

For all "scale" variables goes that they were normalised to range from 0 to 10 , with 10 being the least-favourable situation [34]. Whenever an item was missing on the scale or the combined variables, this item was attributed a value using expectation-maximisation as imputation method [35].

\section{Social class}

The indicators of social class were inspired by Wright's social class scheme and were obtained through the combination of the International Standard Classification of Occupations (ISCO), the International Standard Classification of Education (ISCED), and a question on whether the employee is responsible for supervising other employees. First, three categories were created: managers, supervisors and workers. Employees in occupational group ISCO 1 were considered managers as these occupations are characterised by a high level of organisational control. Non-managers who reported to be responsible for supervising other employees were considered supervisors. All other employees were considered workers. Second, within these three categories, another subdivision was made using ISCED: "unskilled" (up to lower secondary); "semi-skilled" (up to postsecondary non-tertiary); and "experts" (completed tertiary education). Because of sample size limitations, in the multivariate analyses, unskilled and semi-skilled supervisors on one hand, and unskilled and semi-skilled managers on the other were pooled together (resulting in non-expert supervisors and non-expert managers respectively).

\section{Poor mental well-being}

Poor mental well-being was measured by three items from the WHO-5 Well-being Index [36]. The WHO-5 Well-being Index is a measure of positive affect [37]. The ESS 2010 only contained three of the original five items of the WHO-5 Well-being Index [36]. However, the internal consistency of the Well-being Index has 
proven to be excellent. The three items have a Cronbach's alpha of 0.81 across the whole ESS 2010 sample and a Cronbach's alpha of 0.78 across the study sample, which is only marginally lower than the Cronbach's alpha of 0.82 found across the whole ESS 2004 sample which contained all five items from the WHO-5 Well-being index [36]. Consequently, we can be confident that the use of the three-item scale does not lead to different results. The questions included were: (1) over the last two weeks I have felt cheerful and in good spirits, (2) over the last two weeks I have felt calm and relaxed, and (3) over the last two weeks I have felt active and vigorous [37]. Answers range from (1) "All of the time" to (6) "At no time". The item scores were summed and then normalised to a 0 to 10 range.

\section{Psychosocial work characteristics}

The psychosocial work characteristics were measured by the Demand-Control model [29]. Sum scales for low skill discretion and low autonomy were created. Low skill discretion is measured by three items: (1) variety in work; (2) job requires learning new things; and (3) how long for somebody with the right qualifications to learn to do your job well. The low autonomy scale also consists of three items: (1) allowed to decide how daily work is organised; (2) can decide time start/finish work; and (3) allowed to choose/change pace of work. High psychological demands are based on a five-point Likert item: "I have never enough time to get everything done in my job”.

\section{Employment quality}

A multidimensional construct was created to assess employment quality (encompassing employment conditions and relations) [31].

Five indicators were selected to reflect the four dimensions of the quality of employment conditions: contract type, income, irregular and/or unsocial working hours, employment status, and lack of training. Contract type is a categorical variable distinguishing between "permanent contract", "non-permanent contract" and "no contract". Income is measured by combining two questions: a question on the perception of the current household income being sufficient (or not) and a question on the proportion of household income the respondent provides for (main or contributory earner). Measuring income sufficiency at the household is appropriate, since income - although related to individual employment situations - is a concern mostly situated at the household level. The income indicator consists of three categories: "sufficient household income"; "contributory earner with insufficient household income"; and "main earner with insufficient household income". Employment status is a categorical variable distinguishing between "full-time", "part-time" and "involuntary part-time" employment. The involuntary nature of part- time employment is included to control for personal preferences of the employees. Involuntary part-time employees are the respondents who work part-time ( $\leq 35$ hours), but wish to work more hours. Irregular and/or unsocial working hours is measured by 4 items: (1) working weekends; (2) working evenings/nights; (3) working overtime at short notice and (4) intensive working hours. As a first step, a scale for unsocial hours was created, combining "working weekends" with "working evenings and nights" (Pearson correlation $=0.472$ and Cronbach's $\alpha=0.640$ ). Subsequently, the scale for unsocial working hours was added to the indicators for "working overtime at short notice" and "intensive working hours", resulting in an overall scale for irregular and/or unsocial working hours (Cronbach's $\alpha=0.604$ ). Lack of training is measured by a yes-no question on having been on a course for work during the last 12 months.

The quality of employment relations was measured by lack of co-worker support and lack of representation, reflecting the two dimensions of the quality of employment relations. Lack of co-worker support was assessed using the following question: "In current job: I can get support/help from my co-workers when needed", and response categories were "not at all true", "a little true", "quite true" and "very true". This indicator was dichotomised, with the category "not at all true" being considered as the low-support group. Lack of representation is measured through a yes-no question on the membership of a trade union or similar organisation.

In order to control for background characteristics, age was included in our statistical models. Age was recoded into three age groups: $15-29,30-49$ and 50-65. The age categories respond to the three main periods in a working career: lift-off (15-29 years), mid-career period (30-49 years) and end-of career period (50-65 years) [38].

\section{Statistical analyses}

All analyses were sex specific. First, descriptive analyses were conducted. For all categories of the categorical variables, we determined the mean on the poor mental well-being scale. Differences in mean mental well-being between the categories were assessed with a series of one-way analysis of variance tests (ANOVA). For continuous independent variables, Pearson's correlations were calculated between each variable and poor mental wellbeing. Throughout the descriptive analyses, data have been weighted by population weights correcting for population size and by design weights correcting for unequal selection chances. The descriptive analyses were performed using SPSS version 22.

In the multivariate analyses, three-level linear multilevel models were applied to statistically account for the clustering of the sampled employees within research years and countries. Individual employees at level-1 are 
nested within 38 country-year-cohorts at level-2, and country-year-cohorts are nested within 19 European countries at level-3. First, a three-level random intercepts model was estimated as a reference model, only including the individual background variable age. Second, indicators of social class were included in the reference model in order to estimate the distribution of poor mental wellbeing across social classes (Model 1). As this model only provides the differences between social classes as compared to the reference category (unskilled workers), we also fitted Model 1 extended by the interactions between skill level (unskilled, semi-skilled and expert) and social class (worker, supervisor and manager), obtaining similar results (not shown). Third, to test the mediation hypothesis (differential exposure), Model 1 was extended by indicators for the psychosocial work environment, the employment conditions and employment relations in Model 2, 3, and 4 respectively. Finally, to test the moderation hypothesis (differential vulnerability), Model 2, 3 and 4 were extended by the interactions between the indicators of social class and each set of intermediary determinants. All continous scales, except the poor mental well-being scale, were grand mean centered. At all steps, parameter effects of the covariates in relation with poor mental well-being are presented as coefficient estimates, with their related standard errors (SE). Multivariate analyses were carried out using Stata version 12.

\section{Results}

\section{Description of the population}

Table 1 provides the description of the study population, the mean poor mental well-being scores and the statistical differences between groups. The largest part of the population belonged to the class of semi-skilled workers (35.3\% for women and $31.3 \%$ for men). We found marked gender differences in social classes $(10.6 \%$ of men were managers compared to only $5.6 \%$ of women). The mean poor mental well-being score was highest among unskilled workers for women and among expert supervisors for men. Having no contract, an unfavourable income situation, holding an involuntary part-time job (for women), having a lack of training (for men) and a lack of co-worker support implied higher mean poor mental well-being scores. The mean poor mental well-being score was not statistically different for members and non-members of a trade union; therefore being a member of a trade union was omitted from the multivariate analyses. The psychosocial work environment was related to poor mental well-being. Low skill discretion (correlation is 0.07 for women and 0.05 for men), low autonomy (correlation is 0.05 for women and 0.03 for men) and high psychological demands (correlation is 0.07 for women and 0.11 for men) were positively, but weakly correlated to poor mental well-being. The correlation between irregular and/or unsocial working hours and poor mental well-being was also positive and weak (correlation is 0.03 for women and 0.05 for men).

\section{Mediation hypothesis}

Table 2 shows social class, psychosocial work environment, employment conditions and relations to be related to poor mental well-being for the female sample. The reference model indicates that there are significant differences in mean poor mental well-being scores between the different age groups. Employed women between 30 and 49 years have a mean poor mental well-being score that is 0.246 points $(\mathrm{SE}=0.044)$ higher compared to employees between 15 and 29 years of age. Employed women between 50 and 65 years have a mean poor mental well-being score that is 0.230 points $(\mathrm{SE}=0.050)$ higher compared to the youngest age group.

In Model 1, including social class, expert managers on average report the lowest poor mental well-being scores compared to unskilled workers, while supervisors hold an intermediary position. When the indicators for the psychosocial work environment are added (Model 2), all significant associations between social class and mental well-being disappear. Low skill discretion $(b=0.095$; $\mathrm{SE}=$ $0.008)$, low autonomy $(b=0.033 ; \mathrm{SE}=0.007)$ and high psychological demands $(b=0.069$; $S E=0.006)$ are positively associated with poor mental well-being. Adding the indicators for employment conditions (Model 3), also discards all significant associations of mental well-being and social class, except for non-expert supervisors. They still report a poorer mental well-being score than unskilled workers $(b=-0.178 ; S E=0.072)$. Employed women without a contract report a mean poor mental well-being score that is 0.175 points $(\mathrm{SE}=0.082)$ higher compared to female employees holding a permanent contract. Employees who perceive their household income as insufficient report a higher mean poor mental well-being score compared to employees who perceive their household income as sufficient. Employed women working involuntary parttime report a mean poor mental well-being score that is 0.162 points $(\mathrm{SE}=0.071)$ higher compared to full-time workers. Poor mental well-being furthermore increases, as the degree of irregular and/or unsocial working hours increases $(b=0.057 ; S E=0.008)$. When the indicator for employment relations is added (Model 4), all previous significant associations between poor mental well-being and social class remain. Employed women reporting a lack of co-worker support have a poor mental well-being score that is 0.490 points $(\mathrm{SE}=0.071)$ higher compared to those not reporting a lack of support.

Table 3 shows social class, psychosocial work environment, employment conditions and relations to be related to poor mental well-being for the male sample. The reference model indicates significant differences in the mean poor mental well-being scores between the different age 
Table 1 Description of the population studied (number and percentages) and their average score on poor mental well-being (Population in salaried employment, 15-64 years old, ESS Round 2 and 5 (weighted))

\begin{tabular}{|c|c|c|c|c|c|c|c|c|}
\hline \multirow[t]{2}{*}{ Variables } & \multicolumn{4}{|c|}{ Women $(n=13,092)$} & \multicolumn{4}{|c|}{ Men $(n=13,928)$} \\
\hline & $\mathbf{n}$ & $\%$ & $\begin{array}{l}\text { Mean poor mental } \\
\text { well-being score }\end{array}$ & Sig. & $\mathbf{n}$ & $\%$ & $\begin{array}{l}\text { Mean poor mental } \\
\text { well-being score }\end{array}$ & Sig. \\
\hline Social class & & & & 0.000 & & & & 0.048 \\
\hline Workers unskilled & 2067 & 15.8 & 3.9 & & 1958 & 14.1 & 3.3 & \\
\hline Workers semi-skilled & 4626 & 35.3 & 3.6 & & 4363 & 31.3 & 3.4 & \\
\hline Workers experts & 2875 & 22.0 & 3.5 & & 1892 & 13.6 & 3.4 & \\
\hline Supervisors unskilled & 296 & 2.3 & 3.4 & & 584 & 4.2 & 3.2 & \\
\hline Supervisors semi-skilled & 1105 & 8.4 & 3.4 & & 2000 & 14.4 & 3.2 & \\
\hline Supervisors experts & 1387 & 10.6 & 3.6 & & 1652 & 11.9 & 3.4 & \\
\hline Managers unskilled & 92 & 0.7 & 3.5 & & 131 & 0.9 & 3.2 & \\
\hline Managers semi-skilled & 247 & 1.9 & 3.8 & & 458 & 3.3 & 3.4 & \\
\hline Managers experts & 396 & 3.0 & 3.6 & & 890 & 6.4 & 3.3 & \\
\hline Age groups & & & & 0.000 & & & & 0.000 \\
\hline $15-29$ years & 2494 & 19.1 & 3.4 & & 2726 & 19.6 & 3.1 & \\
\hline 30-49 years & 7200 & 55.0 & 3.7 & & 7527 & 54.0 & 3.4 & \\
\hline 50 or more years & 3398 & 26.0 & 3.7 & & 3674 & 26.4 & 3.3 & \\
\hline \multicolumn{9}{|l|}{ Psychosocial work characteristics } \\
\hline Low skill discretion ${ }^{\mathrm{a}}$ & & & $4.5(2.4)$ & & & & $4.1(2.3)$ & \\
\hline Low autonomy ${ }^{a}$ & & & $5.1(2.6)$ & & & & $4.8(2.8)$ & \\
\hline High psychological demands ${ }^{a}$ & & & $5.3(3.0)$ & & & & $5.2(2.9)$ & \\
\hline \multicolumn{9}{|l|}{ Employment conditions } \\
\hline Type of contract & & & & 0.000 & & & & 0.000 \\
\hline Permanent & 10237 & 81.4 & 3.6 & & 11169 & 82.2 & 3.3 & \\
\hline Non-permanent & 1807 & 14.4 & 3.5 & & 1846 & 13.6 & 3.1 & \\
\hline No contract & 529 & 4.2 & 4.1 & & 576 & 4.2 & 3.7 & \\
\hline Income & & & & 0.000 & & & & 0.000 \\
\hline Sufficient household income & 11073 & 84.6 & 3.4 & & 11975 & 86.0 & 3.2 & \\
\hline Contributory earner with insufficient household income & 760 & 5.8 & 4.3 & & 327 & 2.3 & 3.9 & \\
\hline Main earner with insufficient household income & 1258 & 9.6 & 4.6 & & 1626 & 11.7 & 4.1 & \\
\hline Irregular and/or unsocial working hours ${ }^{a}$ & & & $2.6(2.2)$ & & & & $3.8(2.5)$ & \\
\hline \multicolumn{9}{|l|}{ Employment status } \\
\hline Full-time & 8822 & 67.4 & 3.6 & 0.001 & 12859 & 92.3 & 3.3 & 0.118 \\
\hline Part-time & 3474 & 26.5 & 3.7 & & 552 & 4.0 & 3.2 & \\
\hline Involuntary Part-time & 795 & 6.1 & 3.8 & & 517 & 3.7 & 3.4 & \\
\hline Training & & & & 0.154 & & & & 0.001 \\
\hline Yes & 6158 & 47.1 & 3.6 & & 6143 & 44.2 & 3.3 & \\
\hline No & 6911 & 52.9 & 3.6 & & 7743 & 55.8 & 3.4 & \\
\hline \multicolumn{9}{|l|}{ Employment relations } \\
\hline Support from co-workers & & & & 0.000 & & & & 0.000 \\
\hline Yes & 11939 & 92.6 & 3.6 & & 13167 & 95.3 & 3.3 & \\
\hline No & 952 & 7.4 & 4.2 & & 648 & 4.7 & 3.9 & \\
\hline
\end{tabular}




\begin{tabular}{|c|c|c|c|c|c|c|c|}
\hline Member of trade union & & & & 0.424 & & & 0.357 \\
\hline Yes & 2984 & 22.9 & 3.6 & 3277 & 23.6 & 3.3 & \\
\hline No & 10073 & 77.1 & 3.6 & 10617 & 76.4 & 3.3 & \\
\hline Poor mental well-being ${ }^{a}$ & & & $3.6(2.0)$ & & & $3.3(1.9)$ & \\
\hline
\end{tabular}

${ }^{\mathrm{a}} \mathrm{SE}$ between parentheses.

groups. Male employees between 30 and 49 years have a mean poor mental well-being score that is 0.294 points $(\mathrm{SE}=0.041)$ higher compared to employees between 15 and 29 years. Male employees between 50 and 65 years have a mean poor mental well-being that is 0.221 points $(\mathrm{SE}=0.046)$ higher compared to the youngest age group.

The social class indicators are added in Model 1, showing that compared to unskilled workers, non-expert managers report the lowest mean poor mental well-being scores and supervisors hold an intermediary position. When the indicators for the psychosocial work environment are added (Model 2), all significant associations between poor mental well-being and the social class indicators disappear, except for expert workers. Low skill discretion $(b=0.090 ; \mathrm{SE}=0.008)$, low autonomy $(b=0.034$; $\mathrm{SE}=0.007)$ and high psychological demands $(b=0087$; $\mathrm{SE}=0.006)$ are positively associated with poor mental wellbeing. Adding the indicators for employment conditions to Model 1 (Model 3) discards all significant associations of mental well-being and social class, except for expert workers. Employees who perceive their household income as insufficient report a higher mean poor mental wellbeing score compared to employees who perceive their household income as sufficient. Furthermore, poor mental well-being increases as the degree of irregular and/or unsocial working hours increases $(b=0.039$; $\mathrm{SE}=0.007)$. When the indicator for employment relations is added to Model 1 (Model 4), nearly all associations between poor mental well-being and social class become statistically insignificant. Only non-expert supervisors and managers still report a poor mental well-being score that is lower compared to unskilled workers (a poor mental well-being score that is $0.172(\mathrm{SE}=0.059)$ and $0.138(\mathrm{SE}=0.077)$ points lower respectively). Employed men reporting a lack of co-worker support have a poor mental well-being score that is 0.536 points $(\mathrm{SE}=0.077)$ higher compared to those not reporting a lack of support.

\section{Moderation hypothesis}

Table 4 shows Model 2 and 3 extended by the interactions between social class and the indicators for the psychosocial work environment and employment conditions respectively. As the interactions between social class and the indicators of employment relations were not significant, results are not shown. Only significant interactions are presented. Both for men and women, there is effect modification between social class and some of the indicators of the psychosocial work environment and employment conditions. For instance, male expert supervisors and managers report a poorer mental well-being when exposed to high psychological demands, compared to male unskilled workers. Female expert workers report a poorer mental well-being when exposed to low skill discretion and high psychological demands, compared to female unskilled workers. Male non-expert managers report a poorer mental well-being when exposed to an insufficient income while being contributory earner, compared to male unskilled workers.

\section{Discussion}

In this study, Wright's relational social class scheme was used to map out structural social inequalities in employee mental well-being. In addition, indicators for the psychosocial work environment and employment quality accounted for the intermediary determinants of inequalities in mental well-being. We found social class inequalities in the mental well-being of the European working population: for both men and women nonsupervisory non-managerial unskilled workers reported the worst mental well-being. Compared to unskilled workers, managers reported the best mental well-being, while supervisors held an intermediary position. As expected and in accordance with previous studies $[18,19]$, managers showed better mental well-being than the other class positions. Furthermore, our results showed that supervisors reported a better mental well-being than unskilled workers, implying that the location of supervisors within class relations does not result in the worst mental well-being in European employees.

In contrast to our expectations, we did not always find a better mental well-being in experts than non-experts. Among men, supervisors and managers with an expert skill level reported a worse mental well-being than supervisors and managers with lower skill levels. Among women, expert-level supervisors also reported a worse mental well-being than lower-skilled supervisors. Our findings are consistent with previous research [26] and research on status incongruence [39]. Expert supervisors and managers can be considered high-status congruents, that is workers who simultaneously hold a less exploited, 
Table 2 Multilevel models for poor mental well-being in 14,164 employed women aged 15-65 nested within 38 year-cohorts in 19 European countries (ESS 2004/5 and 2010)

\begin{tabular}{|c|c|c|c|c|c|}
\hline & $\begin{array}{l}\text { Reference model } \\
\text { b (SE) }\end{array}$ & $\begin{array}{l}\text { Model } 1 \\
\text { b (SE) }\end{array}$ & $\begin{array}{l}\text { Model } 2 \\
\text { b (SE) }\end{array}$ & $\begin{array}{l}\text { Model } 3 \\
\text { b (SE) }\end{array}$ & $\begin{array}{l}\text { Model } 4 \\
\text { b (SE) }\end{array}$ \\
\hline \multicolumn{6}{|l|}{ Fixed effects } \\
\hline Constant & $3.368(0.084)^{* * *}$ & $3.529(0.096)^{* * *}$ & $3.352(0.098)^{* * *}$ & $3.048(0.096)^{* * *}$ & $3.480(0.096)^{* * *}$ \\
\hline \multicolumn{6}{|l|}{ Individual characteristics } \\
\hline \multicolumn{6}{|l|}{ Age } \\
\hline \multicolumn{6}{|l|}{$15-29$ years (ref.) } \\
\hline $30-49$ years & $0.246(0.044)^{* * *}$ & $0.247(0.044)^{* * *}$ & $0.248(0.044)^{* * *}$ & $0.258(0.045)^{* * *}$ & $0.240(0.044)^{* * *}$ \\
\hline 50 years and older & $0.230(0.050)^{* * *}$ & $0.214(0.050)^{* * *}$ & $0.231(0.049)^{* * *}$ & $0.266(0.051)^{* * *}$ & $0.203(0.050)^{* * *}$ \\
\hline \multicolumn{6}{|l|}{ Social Class } \\
\hline \multicolumn{6}{|l|}{ Unskilled workers (ref.) } \\
\hline Semi-skilled workers & & $-0.144(0.056)^{* *}$ & $-0.046(0.056)$ & $-0.099(0.056)$ & $-0.121(0.056)^{*}$ \\
\hline Expert workers & & $-0.181(0.059)^{* *}$ & $0.022(0.061)$ & $-0.031(0.060)$ & $-0.146(0.059)^{*}$ \\
\hline Non-expert supervisors & & $-0.252(0.072)^{* * *}$ & $-0.064(0.073)$ & $-0.178(0.072)^{*}$ & $-0.218(0.072)^{* *}$ \\
\hline Expert supervisors & & $-0.182(0.069)^{* *}$ & $0.042(0.073)$ & $-0.059(0.071)$ & $-0.140(0.069)^{*}$ \\
\hline Non-expert managers & & $-0.212(0.118)$ & $0.024(0.119)$ & $-0.113(0.117)$ & $-0.187(0.118)$ \\
\hline Expert managers & & $-0.307(0.100)^{* *}$ & $-0.022(0.103)$ & $-0.158(0.101)$ & $-0.269(0.100)^{* *}$ \\
\hline \multicolumn{6}{|c|}{ Psychosocial work environment } \\
\hline Low skill discretion & & & $0.095(0.008)^{* * *}$ & & \\
\hline Low autonomy & & & $0.033(0.007)^{* * *}$ & & \\
\hline High psychological demands & & & $0.069(0.006)^{* * *}$ & & \\
\hline
\end{tabular}

\section{Employment conditions}

Contract type

Permanent (ref.)

Non-permanent

No contract

Income

Sufficient household income (ref.)

Contributory earner with insufficient household income

Main earner with insufficient household income

Irregular and/or unsocial hours

Employment status

Full-time (ref.)

Part-time

Involuntary part-time

Lack of training

\section{Employment relations}

Lack of support

Random effects ${ }^{a}$

Level 1 variance

$3.664(0.044)$
$0.035(0.015)$
$0.088(0.037)$
-29338.4

$3.660(0.044)$
$0.034(0.015)$
$0.088(0.036)$
-29329.3

$3.586(0.043)$

$3.544(0.042)$

$3.648(0.044)$

Level 2 variance

$0.032(0.014)$

$0.029(0.013)$

$0.032(0.014)$

Level 3 variance

$0.090(0.037)$

$0.058(0.026)$

$0.087(0.036)$

- 2 loglikelihood

$-29185.3$

$-29097.5$

$-29305.4$

${ }^{*} p \leq 0.05 ;{ }^{* *} p \leq 0.01 ;{ }^{* * *} p \leq 0.001$.

${ }^{a}$ All random effects are significantly different from zero at $95 \%$ confidence. 
Table 3 Multilevel models for poor mental well-being in 14,583 employed men aged 15-65 nested within 38 year-cohorts in 19 European countries (ESS 2004/5 and 2010)

\begin{tabular}{|c|c|c|c|c|c|}
\hline & $\begin{array}{l}\text { Reference model } \\
\text { b (SE) }\end{array}$ & $\begin{array}{l}\text { Model } 1 \\
\text { b (SE) }\end{array}$ & $\begin{array}{l}\text { Model } 2 \\
\text { b (SE) }\end{array}$ & $\begin{array}{l}\text { Model } 3 \\
\text { b (SE) }\end{array}$ & $\begin{array}{l}\text { Model } 4 \\
\text { b (SE) }\end{array}$ \\
\hline \multicolumn{6}{|l|}{ Fixed effects } \\
\hline Constant & $3.094(0.086)^{* * *}$ & $3.194(0.096)^{* * *}$ & $3.108(0.097)^{* * *}$ & $2.809(0.096)^{* * *}$ & $3.165(0.096)^{* * *}$ \\
\hline \multicolumn{6}{|l|}{ Individual characteristics } \\
\hline \multicolumn{6}{|l|}{ Age } \\
\hline \multicolumn{6}{|l|}{$15-29$ years (ref.) } \\
\hline $30-49$ years & $0.294(0.041)^{* * *}$ & $0.305(0.041)^{* * *}$ & $0.301(0.041)^{* * *}$ & $0.270(0.042)^{* * * *}$ & $0.298(0.041)^{* * *}$ \\
\hline 50 years and older & $0.221(0.046)^{* * *}$ & $0.228(0.046)^{* * *}$ & $0.248(0.046)^{* * *}$ & $0.234(0.047)^{* * *}$ & $0.217(0.046)^{* * *}$ \\
\hline \multicolumn{6}{|l|}{ Social Class } \\
\hline \multicolumn{6}{|l|}{ Unskilled workers (ref.) } \\
\hline Semi-skilled workers & & $-0.108(0.054)^{*}$ & $-0.052(0.053)$ & $-0.038(0.054)$ & $-0.096(0.054)$ \\
\hline Expert workers & & $-0.020(0.061)$ & $0.127(0.062)^{*}$ & $0.144(0.062)^{*}$ & $-0.007(0.061)$ \\
\hline Non-expert supervisors & & $-0.185(0.059)^{* *}$ & $-0.045(0.060)$ & $-0.098(0.059)$ & $-0.172(0.059)^{* *}$ \\
\hline Expert supervisors & & $-0.147(0.065)^{*}$ & $0.038(0.068)$ & $-0.003(0.067)$ & $-0.123(0.065)$ \\
\hline Non-expert managers & & $-0.247(0.091)^{* *}$ & $-0.060(0.092)$ & $-0.130(0.091)$ & $-0.224(0.091)^{*}$ \\
\hline Expert managers & & $-0.160(0.077)^{*}$ & $0.040(0.080)$ & $-0.021(0.079)$ & $-0.138(0.077)$ \\
\hline \multicolumn{6}{|c|}{ Psychosocial work environment } \\
\hline Low skill discretion & & & $0.090(0.008)^{* * *}$ & & \\
\hline Low autonomy & & & $0.034(0.007)^{* * *}$ & & \\
\hline High psychological demands & & & $0.087(0.006)^{* * *}$ & & \\
\hline
\end{tabular}

\section{Employment conditions}

Contract type

Permanent (ref.)

Non-permanent

No contract

Income

Sufficient household income (ref.)

Contributory earner with insufficient household income

Main earner with insufficient household income

Irregular and/or unsocial hours

Employment status

Full-time (ref.)

Part-time

Involuntary part-time

Lack of training

\section{Employment relations}

Lack of support

Random effects ${ }^{a}$

Level 1 variance

$3.379(0.040)$
$0.023(0.011)$
$0.105(0.040)$
-29612.5

$3.374(0.040)$

$3.289(0.039)$

$3.293(0.039)$

$3.363(0.039)$

Level 2 variance

$0.023(0.011)$

$0.025(0.012)$

$0.020(0.010)$

$0.106(0.040)$

$0.105(0.040)$

$0.075(0.029)$

$0.022(0.011)$

Level 3 variance

$-29602.9$

$-29419.7$

$-29421.1$

$0.105(0.039)$

${ }^{*} p \leq 0.05 ;{ }^{* *} p \leq 0.01 ;{ }^{* * *} p \leq 0.001$.

${ }^{a}$ All random effects are significantly different from zero at $95 \%$ confidence. 
Table 4 Summary of significant interaction effects in the multilevel models for poor mental well-being in European employees aged 15-65 nested within 38 year-cohorts in 19 European countries (ESS 2004/5 and 2010)

\begin{tabular}{|c|c|c|c|c|c|}
\hline $\begin{array}{l}\text { Interactions with } \\
\text { psychosocial work } \\
\text { environment }\end{array}$ & $\begin{array}{l}\text { Extended model } 2 \\
\text { for employed women } \\
\text { b (SE) }\end{array}$ & $\begin{array}{l}\text { Extended model } 2 \\
\text { for employed men } \\
\text { b (SE) }\end{array}$ & $\begin{array}{l}\text { Interactions with } \\
\text { employment } \\
\text { conditions }\end{array}$ & $\begin{array}{l}\text { Extended model } 3 \\
\text { for employed women } \\
\text { b (SE) }\end{array}$ & $\begin{array}{l}\text { Extended model } 3 \\
\text { for employed men } \\
\text { b (SE) }\end{array}$ \\
\hline $\begin{array}{l}\text { Semi-skilled workers } x \\
\text { Low skill discretion }\end{array}$ & $0.055(0.023)^{*}$ & & $\begin{array}{l}\text { Semi-skilled workers x Contr. } \\
\text { earner w. in. income }\end{array}$ & $-0.473(0.188)^{*}$ & \\
\hline $\begin{array}{l}\text { Semi-skilled workers } x \\
\text { High psy. demands }\end{array}$ & $0.042(0.019)^{*}$ & & $\begin{array}{l}\text { Semi-skilled workers } \times \text { Lack } \\
\text { of training }\end{array}$ & $-0.238(0.118)^{*}$ & \\
\hline $\begin{array}{l}\text { Expert workers x Low } \\
\text { skill discretion }\end{array}$ & $0.059(0.034)^{*}$ & & $\begin{array}{l}\text { Expert workers x Main earner } \\
\text { w. in. income }\end{array}$ & $-0.495(0.171)^{* *}$ & \\
\hline $\begin{array}{l}\text { Expert workers } \times \text { High } \\
\text { psy. demands }\end{array}$ & $0.062(0.020)^{* *}$ & & $\begin{array}{l}\text { Expert workers } \times \text { Lack of } \\
\text { training }\end{array}$ & $-0.312(0.125)^{*}$ & \\
\hline $\begin{array}{l}\text { Non-expert managers } x \\
\text { Low autonomy }\end{array}$ & $-0.115(0.047)^{*}$ & & $\begin{array}{l}\text { Non-expert supervisors } x \\
\text { Main earner } w \text {. in. income }\end{array}$ & $-0.478(0.209)^{*}$ & \\
\hline $\begin{array}{l}\text { Non-expert managers } x \\
\text { High psy. demands }\end{array}$ & $0.088(0.041)^{*}$ & & $\begin{array}{l}\text { Non-expert managers } x \\
\text { Involuntary part-time }\end{array}$ & $1.489(0.600)^{*}$ & $1.141(0.509)^{*}$ \\
\hline $\begin{array}{l}\text { Expert managers } \times \text { Low } \\
\text { autonomy }\end{array}$ & $-0.133(0.048)^{* *}$ & & $\begin{array}{l}\text { Non-expert managers } \times \text { Lack } \\
\text { of training }\end{array}$ & $-0.696(0.239)^{* *}$ & \\
\hline $\begin{array}{l}\text { Expert supervisors } x \\
\text { High psy. demands }\end{array}$ & & $0.053(0.24)^{*}$ & $\begin{array}{l}\text { Non-expert managers } x \\
\text { Contr. earner w. in. income }\end{array}$ & & $0.571(0.845)^{* *}$ \\
\hline
\end{tabular}

Expert managers $\times$ High $\quad 0.080(0.028)^{* *}$

psy. demands

${ }^{*} p \leq 0.05 ;{ }^{* *} p \leq 0.01$.

Abbreviations: psy.: psychological; Contr.: Contributory; w. in. income: with insufficient household income.

more empowered class location on the organisational control dimension and on the skill dimension. According to Lundberg et al. [39] high-status congruent individuals show an elevated risk for experiencing shaming, that is the sensation of not being regarded and respected in the way one thinks one deserves to be. Shaming experiences are a primary producer of poor mental well-being [39]. Expert managers and supervisors are less exploited. Yet, they also occupy a "contradictory class location" [25]. They can still experience events of domination, for example being disciplined for a poor performance by their own superiors (their owners or their boards). These disciplinary measures are more likely to offend them and evoke feelings of shame, because of inadequate confirmation of their social location by others [39]. In other words, although expert supervisors and managers are less exploited compared to other employees, the external sanctions they do experience may have a larger impact on their well-being. The finding that occupying an expert location is not always protective of mental well-being is in line with Wright's indicators of skills/ credentials as a measure of social class, rather than with social stratification theory.

Our study also sheds some light on the mechanisms that mediate/moderate the relationship between social class and poor mental well-being among men and women. As regards the moderation hypothesis, both for employed men and women, there is effect modification between social class and some of the indicators of the psychosocial work environment and employment conditions, implying differential vulnerability. As regards the mediation hypothesis, we found, in accordance with previous research on self-reported health [18], that explaining the associations between social class and mental well-being involved different mediating factors for men and women. Our results showed that an unfavourable psychosocial work environment and low-quality employment conditions mediate the relation between social class and mental 
well-being for both men and women. However, low-quality employment relations only mediate the relation between social class and mental well-being for men. An explanation for this could be found in differences in social roles and in the different meaning of employment relations for men and women [40]. Although both men and women place high value on the employee and homemaker roles [41], typically, employment relations are of higher importance to men, than to women. Historically and culturally throughout the male breadwinner model, men attach more meaning to the labour role which is key to their identity, while the labour role of women is often secondary to their caring/parenting role. Yet, male nonexpert supervisors and managers still experience better mental well-being than male unskilled workers, even after accounting for employment relations. An explanation for this might be that non-expert supervisors and managers reached their position by upward career promotion, rather than as a consequence of a high education. Upward mobility changes the social location of people, but not necessarily their values and expectations. On the contrary, values and expectations will often differ from those of the new sociocultural context [39]. As a consequence, the expectations of non-expert supervisors and managers about the employment relations could still be similar to the expectations of the lower social classes, and thus be minified. Therefore, the employment relations may have no mediating effect on the relation between mental well-being and social class for these classes.

Interestingly, male expert workers reported the worst mental well-being after controlling for the adverse psychosocial work environment and employment conditions. This finding is consistent with the finding that negatively incongruent individuals report a higher frequency of poor mental well-being, compared to other groups [39]. Expert workers can be considered negatively incongruent, as they hold a more exploited, less empowered class location on the organisational control dimension and a less exploited, more empowered class location on the skill dimension.

Due to the use of secondary data, our study bears some limitations. First, our data are derived from a cross-sectional sample, so we cannot formally establish the causal direction of the relationships under study. Second, the ISCED-classification used to operationalize skills and expertise is only a proxy for the underlying theoretical concept, as skills and expertise may be recognised without being formally certified by an educational degree [25]. Including skills and expertise other than acquired through schooling might strengthen the observed theory. Third, the dataset used in this study is a pooled dataset containing data from 2004/2005 and 2010. However, as of 2008, an economic and social crisis has taken place in European countries. This economic crisis has shown to impact mental health and even suicide mortality
$[42,43]$. However, our models show a small between-yearwithin-country variance, indicating that the average mental well-being of employees in a certain country was not that different in 2004/5 compared to 2010.

The present study also has several strengths. First, a clear strength of this study is the use of proxies of relational indicators of social class. Our results underscore the importance of relational indicators of social class for assessing social inequalities in mental health of European employees. They provide a complementary approach to stratification indicators in social epidemiology and public health research. Second, although several studies have underscored that explaining social inequalities in health involves mediation and moderation mechanisms [22,26,27], few studies have investigated these mechanisms simultaneously.

\section{Conclusions}

Social class is related to mental well-being in European employees. From a policy perspective, this study implies that better employee mental well-being and less social inequalities could be achieved by initiatives addressing the unequal social relations generated by structural positions in the labour process, such as regular meetings between representatives of employers and different groups of employees. Vertical bureaucracy, typically associated with Fordist systems, should be transformed into more horizontal organisational structures [44]. Moreover, our results underline the importance of the psychosocial work environment, of the employment conditions and relations for understanding social class inequalities in mental well-being and for improving the mental well-being of European employees.

\section{Competing interests}

The authors declare that they have no competing interests.

\section{Authors' contributions}

DMD and VRC have contributed to the conception and design of the study. DMD prepared the data and performed the statistical analyses. All authors were involved in the interpretation of the data and in drafting and revising the manuscript. All authors read and approved the final manuscript.

\section{Acknowledgements}

The research for this article has been supported by the Research council of the Vrije Universiteit Brussel, Belgium (research grant 'OZR2094'), by the Research Foundation Flanders (G.0440.09 N) and the SOPHIE-project which has received funding from the European Community's Seventh Framework Program Health (FP7/2007-2013) under grant agreement no. 278173.

\section{Author details}

'Department of Sociology, Vrije Universiteit Brussel, Pleinlaan 2, 1050 Brussel, Belgium. ${ }^{2}$ Health Inequalities Research Group, Employment Conditions Knowledge Network (GREDS\Emconet), Universitat Pompeu Fabra, Plaça de la Mercè 10-12, 08002 Barcelona, Spain. ${ }^{3}$ Bloomberg Faculty of Nursing, University of Toronto, Toronto, ON M5T 1P8, Canada. ${ }^{4}$ College of Health Sciences, Korea University, Seoul 136-703, Korea.

Received: 3 April 2014 Accepted: 26 August 2014

Published: 9 September 2014 


\section{References}

1. Löve J, Hensing G, Holmgren K, Torén K: Explaining the social gradient in sickness absence: a study of a general working population in Sweden. BMC Public Health 2013, 13:545.

2. Stansfeld SA, Head J, Fuhrer R, Wardle J, Cattell V: Social inequalities in depressive symptoms and physical functioning in the Whitehall II study: exploring a common cause explanation. J Epidemiol Community Heal 2003, 57:361-367.

3. Lahelma E, Martikainen P, Laaksonen M, Aittomäki A: Pathways between socioeconomic determinants of health. J Epidemiol Community Heal 2004, 58:327-332.

4. Stansfeld S, Head J, Marmot MG: Explaining social class differences in depression and well-being. Soc Psychiatry Psychiatr Epidemiol 1998, 33:1-9

5. Fryers T, Melzer D, Jenkins R: Social inequalities and the common mental disorders: a systematic review of the evidence. Soc Psychiatry Psychiatr Epidemiol 2003, 38:229-237.

6. Keyes CLM: The mental health continuum: From languishing to flourishing in life. J Heal Soc Res 2002, 43:207-222.

7. Diener E: Assessing Well-Being. New York: Spinger; 2009:274

8. Bartlett CJ, Coles EC: Psychological health and well-being: why and how should public health specialists measure it? Part 1: Rationale and methods of the investigation, and review of psychiatric epidemiology. J Public Health Med 1998, 20:281-287.

9. Koopmans PC, Bültmann U, Roelen CAM, Hoedeman R, van der Klink JJL, Groothoff JW: Recurrence of sickness absence due to common mental disorders. Int Arch Occup Environ Health 2011, 84:193-201.

10. Lahelma E, Martikainen P, Rahkonen O, Roos E, Saastamoinen P: Occupational class inequalities across key domains of health: Results from the Helsinki Health Study. Eur J Public Health 2005, 15:504-510.

11. Laaksonen E, Martikainen P, Lahelma E, Lallukka T, Rahkonen O, Head J, Marmot M: Socioeconomic circumstances and common mental disorders among Finnish and British public sector employees: evidence from the Helsinki Health Study and the Whitehall II Study. Int J Epidemiol 2007, 36:776-786.

12. Pinto-Meza A, Moneta MV, Alonso J, Angermeyer MC: Social inequalties in mental health: results from the EU contribution to the World Mental Health Surveys Initiative. Soc Psychiatry Psychiatr Epidemiol 2013, 48:173-181.

13. Molarius A, Berglund $K$, Eriksson $C$, Eriksson HG, Lindén-Boström $M$, Nordström E, Persson C, Sahlqvist L, Starrin B, Ydreborg B: Mental health symptoms in relation to socio-economic conditions and lifestyle factors a population-based study in Sweden. BMC Public Health 2009, 9:302.

14. Muntaner C, Borrell C, Chung H: Class Relations, Economic Inequality and Mental Health: Why Social Class Matters to the Sociology of Mental Health. In Ment Heal Soc mirror. US: Springer; 2007:127-141.

15. Muntaner C, O'Campo P: A critical appraisal of the demand/control model of the psychocial work environment: Epistemological, social, behavioral and class considerations. Soc Sci Med 1993, 36:1509-1517.

16. Muntaner C, Borrell C, Benach J, Pasarin MI, Fernandez E: The associations of social class and social stratification with patterns of general and mental health in a Spanish population. Int J Epidemiol 2003, 32:950-958.

17. Muntaner C, Ng E, Vanroelen C, Christ S, Eaton WW: Social Stratification, Social Closure, and Social Class as Determinants of Mental Health Disparities. In Handbooks Sociol Soc Res. Edited by DeLamater J. Springer: 2013:205-227.

18. Borrell C, Muntaner C, Benach J, Artazcoz L: Social class and self-reported health status among men and women: what is the role of work organisation, household material standards and household labour? Soc Sci Med 2004, 58:1869-1887.

19. Muntaner C, Eaton WW, Diala C, Kessler RC, Sorlie PD: Social class, assets, organizational control and the prevalence of common groups of psychiatric disorders. Soc Sci Med 1998, 47:2043-2053.

20. Muntaner C, Borrell C, Vanroelen C, Chung H, Benach J, Kim IH, Ng E: Employment relations, social class and health: a review and analysis of conceptual and measurement alternatives. Soc Sci Med 2010, 71:2130-2140

21. Huppert FA, So TTC: Flourishing Across Europe: Application of a New Conceptual Framework for Defining Well-Being. Soc Indic Res 2013, 110:837-861.

22. Hoven $\mathrm{H}$, Siegrist J: Work characteristics, socioeconomic position and health: a systematic review of mediation and moderation effects in prospective studies. Occup Environ Med 2013, 70:663-669.
23. Turner RJ, Lloyd DA: The stress process and the social distribution of depression. J Health Soc Behav 1999, 40:374-404.

24. Solar O, Irwin A: A Conceptual Framework for Action on the Social Determinats of Health. Social Determinants of Health Discussion Paper 2. Geneva: World Health Organization; 2010:75. Discussion.

25. Wright EO: Class Counts. Cambridge: Cambridge University Press; 1997:289

26. Vanroelen C, Levecque K, LouckX F: Differential exposure and differential vulnerability as countracting forces linking the psychosocial work environment to socio-economic health diffrences. J Epidemiol Community Heal 2010, 64:866-873.

27. Siegrist J, Marmot M: Health inequalities and the psychosocial environment-two scientific challenges. Soc Sci Med 2004, 58:1463-1473.

28. Lunau T, Wahrendorf M, Dragano N, Siegrist J: Work stress and depressive symptoms in older employees: impact of national labour and social policies. BMC Public Health 2013, 13:1086.

29. Karasek R, Theorell T: Healthy Work. Stress, Productivity, and the Reconstruction of Working Life. New York: Basic Books; 1990:381.

30. Bardasi E, Francesconi M: The impact of atypical employment on individual wellbeing: evidence from a panel of British workers. Soc Sci Med 2004, 58:1671-1688.

31. Eurofound: Quality of Employment Conditions and Employment Relations in Europe. Dublin: Publications Office of the European Union; 2013:64.

32. Biron $M$, Bamberger $P$ : The impact of structural empowerment on individual well-being and performance: Taking agent preferences, self-efficacy and operational constraints into account. Hum Relations 2010, 63:163-191.

33. Benach J, Gimeno D, Benavides FG, Martínez JM, Del M, Torné MAR: Types of employment and health in the European Union. Changes from 1995 to 2000. Eur J Public Health 2004, 14:314-321.

34. Tangian A: Is Flexible Work Precarious? A Study Based on the 4th European Survey of Working Conditions 2005. Düsseldorf: Institute for Economic and Social Sciences (WSI); 2007:77. WSI-Diskussionspapier.

35. Allison P: Missing Data. Quantitative Applications in the Social Sciences. London: SAGE publications Ltd; 2001:104.

36. ESS: Round 5 Module on Work, Family and Well-Being - Final Question Design Template. City University London: Centre for Comparative Social Surveys; 2011:1-59.

37. Bech P, Olsen LR, Kjoller M, Rasmussen NK: Measuring well-being rather than the absence of distress symptoms: a comparison of the SF-36 Mental Health subscale and the WHO-Five Well-Being Scale. Int $J$ Methods Psychiatr Res 2003, 12:85-91.

38. Vanroelen C: Work-Related Health Complaints in a Post-Fordist Labour Force. A Sociology of Work-Related Socio-Economic Health Inequalities. Brussels: VUBPRESS; 2009:384

39. Lundberg J, Kristenson M, Starrin B: Status incongruence revisited: associations with shame and mental wellbeing. Sociol Health IIIn 2009, 31:478-493.

40. Thoits PA: Stress, Coping, and Social Support Processes: Where Are We? What Next? J Health Soc Behav 1995, 35(Extra Issue):53-79.

41. Barnett RC, Hyde JS: Women, Men, Work and Family. An Expansionist Theory. Am Psychol 2001, 56:781-796.

42. Karanikolos M, Mladovsky P, Cylus J, Thomson S, Basu S, Stuckler D, Mackenbach JP, McKee M: Financial crisis, austerity, and health in Europe. Lancet 2013, 381:1323-1331.

43. Wahlbeck K, McDaid D: Actions to alleviate the mental health impact of the economic crisis. World psychiatry 2012, 11:139-145.

44. Edgell S: Sociology of Work. Continuity and Change in Paid and Unpaid Work. London: SAGE publications Ltd; 2006:244.

doi:10.1186/1471-2458-14-938

Cite this article as: De Moortel et al: Structural and intermediary determinants of social inequalities in the mental well-being of European workers: a relational approach. BMC Public Health 2014 14:938. 